\title{
Virtuous Waters in the Twenty-First Century
}

Every weekend people from Toluca, Mexico City, and other nearby areas pour into Ixtapan de la Sal to take the waters. Those who can afford it go for a few days of relaxation around a pool at a fancy hotel or private home. Many families will visit the Ixtapan Aquatic Park, a somewhat-pricey waterpark with slides, rides, and restaurants, but it is mostly the old folks who head for a soak at the park's hot springs bathhouse. The older people remember when the bathhouse was connected to the hotel, before the San Román family divided their property and the aquatic park was built to appeal to younger generations of customers seeking more exciting interactions with Ixtapan's waters. The aquatic park also has a luxurious spa with thermal waters to serve upscale guests. Visitors to the town with more modest resources perhaps choose a smaller hotel with a pool, and those with less will stay at a budget hotel or pension in town and walk to the municipal bathhouse, which is about a third of the price of the waterpark, but still offers various pools, a waterslide, and a restaurant.

Many of those at the municipal bathhouse come to Ixtapan to soak in the therapeutic hot springwaters. "The waters are salty," a middle-aged man told me as we lounged in one of the two small hot pools at the municipal bathhouse, "not like the sulfurous waters of Hidalgo. These ones are good for reducing blood pressure." The small hot pools were considered therapeutic by most everyone sitting in them, and the cooler large pool at the center of the complex was more for fun, as evidenced by the kids, babies, and parents splashing around. An older woman said that the salty waters of the hot pool were good for her rheumatism, and she moved to let the water flow over her as it emerged from an opening in the floor at the center of the pool. I hauled myself from the hot pool to the murky, cool waters of the nearby 


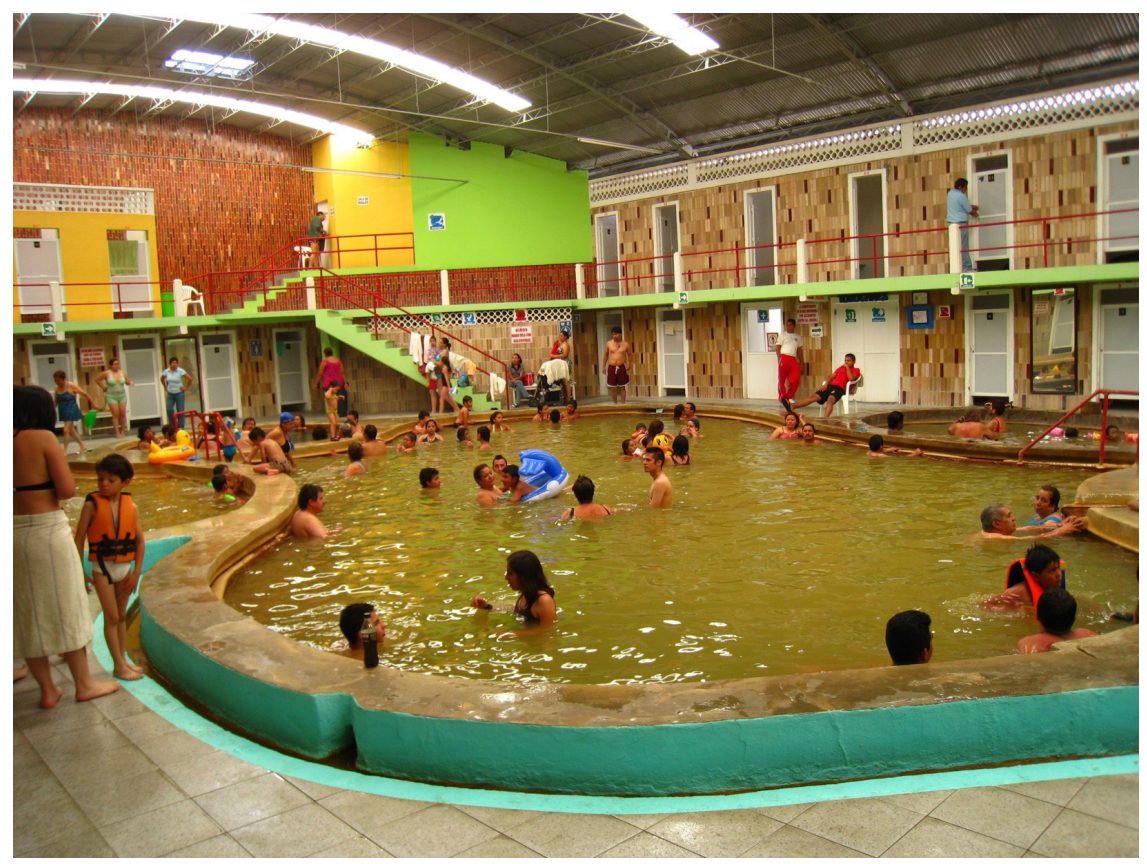

FIGURE 22. A weekend afternoon in the Municipal Bathhouse, Ixtapan de la Sal, 2009.

Photograph by author.

mud pool, where a few men and women sat plastered with the dark brown mud of the hot springs. "It removes toxins," an overweight young man told me as we sat with the mud drying on our faces, looking a little like aquatic raccoons. A pair of well-dressed young women had set up a table nearby, looking out of place in their high heels. They were selling some sort of dietary supplement concocted from nopal cactus, a traditional food in highland Mexico reputed to alleviate diabetes.

I followed a busload of elderly folks as they filed into the bathhouse and entered a separate hydrotherapy room, guided by a younger woman in white pants and jacket who looked and acted like a nurse, giving instructions about how best to take advantage of the healing powers of the Jacuzzi jets and waters. The elderly patients were taking a day trip to treat assorted complaints: mostly high blood pressure, aching joints, and obesity. I soon found out that access to this room required an additional fee, and it was clearly set apart in its ambience from the ludic space of the bathhouse's main pools. The hydrotherapy techniques were prescribed and required more control. Like the hot spring pools it was a healing space, but the bathing practices were regimented and it had a more clinical feel.

Heterogeneous waters continue to attract people to their virtues, but the knowledge and use of these waters is not as common, perhaps, as it once was. Ixtapan 


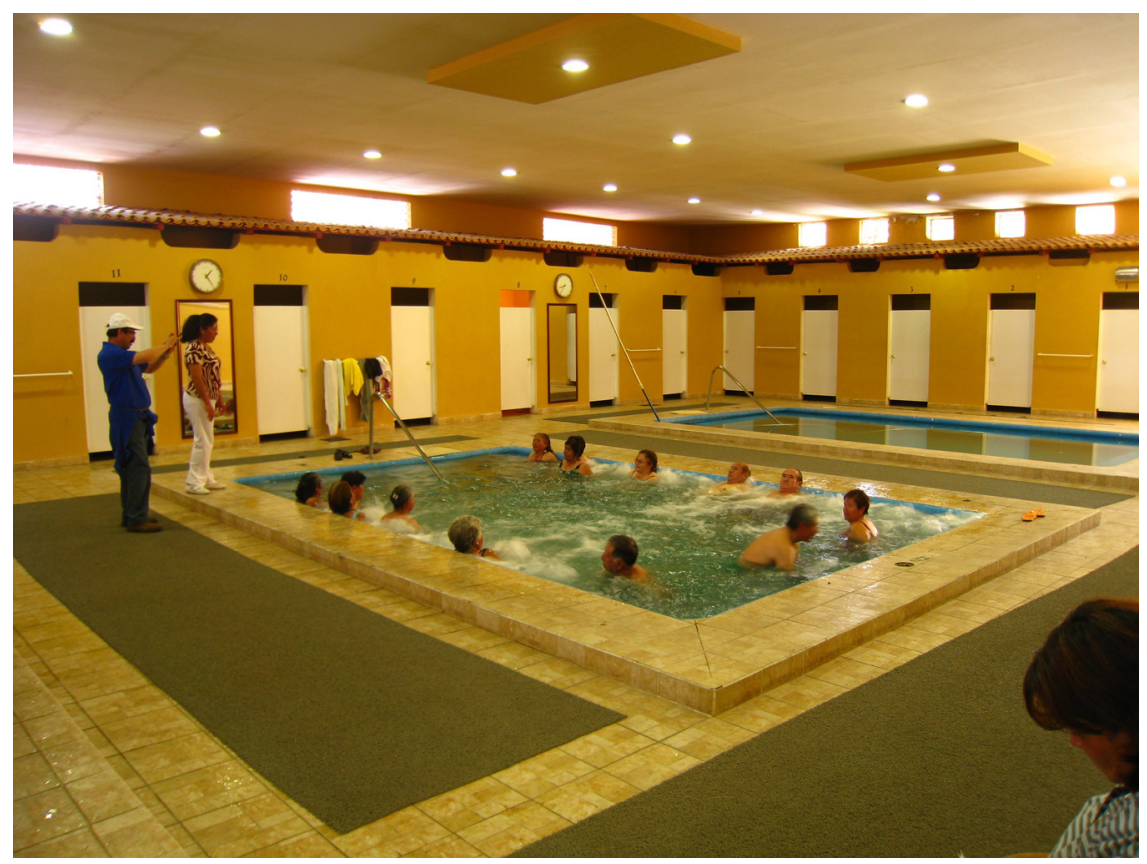

FIGURE 23. Hydrotherapy room, Municipal Bathhouse, Ixtapan de la Sal, 2009. Photograph by author.

de la Sal might be the best-known spa town in Mexico. It is close to Mexico City and continues to thrive as a hub of tourism, mostly national. Ixtapan's waters still attract many visitors, but the great majority of today's visitors to the town will not bathe in the mineral waters that made it famous. The number of hot springs has not increased, while the numbers of hotels, pools, spas, and visitors have skyrocketed over the last century to accommodate growing numbers of tourists. The upscale guests at the Hotel Ixtapan, for example, might choose an aromatherapy massage at the new "Holistic Spa," or maybe take a yoga class or sunbathe by the pool. Those still interested in soaking in the mineral waters will have to leave that hotel through a gate to get to the old bathhouse, now on the property of the neighboring Ixtapan Aquatic Park, or they may use the individualized bathing rooms of the marble-and-onyx-covered Ixtapan Spa, built in the 1960s. The old bathhouse is something of a relic, "rubble" of a bygone moment. ${ }^{1}$ The Ixtapan Spa from the 196os is dated in its appearance, and its mineral baths do not, the hotel recognizes, reflect "new health and fitness trends" such as those offered at the "Holistic Spa". Some other boutique hotels in Ixtapan have built temazcal steambaths for guests seeking the curative and spiritual dimensions of pre-Hispanic and indigenous bathing practices. Ixtapan's mineral springs still bubble from the 
ground, but most people choose a bathing experience in which mineral waters do not play a central role.

Visitors to other historically famous mineral springs in Mexico encounter a similar situation. Little remains of the bathhouse row in Aguascalientes, and in Tehuacán the efficacious, virtuous waters that drew people to the town for centuries are rather hard to find these days. The source of the Peñafiel mineral waters can be seen but not touched or even photographed, deep in an underground cavern below the bottling plant owned now by the Dr. Pepper-Snapple group. The El Riego and Garci-Crespo hotels are long gone, and the hotels that serve visitors do not offer mineral waters for bathing; they might offer other present-day "spa" services such as massages, face masks, or chocolate "therapy."3 The mineral waters of Tehuacán are now only accessible for bathing at the San Lorenzo spring, which supplies a shady, popular waterpark two kilometers from the town center. At San Lorenzo, the communitarian form of ejido property has conserved the springs as a common-pool resource and has served as a barrier to primitive accumulation. Topo Chico, on the other hand, is now an industrial zone of the city of Monterrey, and the only hint that hot springs once sprang forth there is a private museum dedicated to the history of the Topo Chico mineral water company. There are plenty of spas advertised in Monterrey_ "nail" spas, "day" spas, "medical" spas-but none of these involve bathing, drinking, or otherwise interacting with mineral waters.

The mineral spring in the "El Pocito" church in La Villa de Guadalupe can be smelled and not seen: its sulfurous scent wafts up from a well that remains grated to prevent anyone from interacting with its waters. "El Pocito" is now known for its architecture rather than for the fact that it enshrines a centuries-old engagement with the heterogeneous waters of the Valley of Mexico. The nineteenthcentury bathhouse founded by Liceaga in front of the train station in La Villa de Guadalupe is long vanished, and the springwaters that served as a pilgrimage destination for centuries are only symbolically present in the elaborate fountains, pools, and waterfalls that have been built into the side of the Tepeyac hill that rises above the Basilica of Guadalupe and its uber-iconic depiction of the Virgen de Guadalupe. These waters are off-limits to visitors, who will also find no holy water offered at the entrance of the various churches at the site. But traditions are slow to fade, and every day dozens of young parents bring their babies to be baptized in the "Bautisterio" (baptismal chapel), a large building next to the basilica dedicated solely to that important watery sacrament.

In Peñón de los Baños, the thermal mineral waters have simply been neglected as capital chases better chances of accumulation. But because they are not used for bottling or spa tourism, the therapeutic uses of the waters stand out. The bathhouse at Peñón de los Baños is today located on the dark, decrepit, and austere bottom floor of a brick and cement building in a drab working-class neighborhood in Mexico City. The modest business serves folks who seek a medical treatment; there is no luxury, no leisure. Instead there are private rooms with placeres and hot 


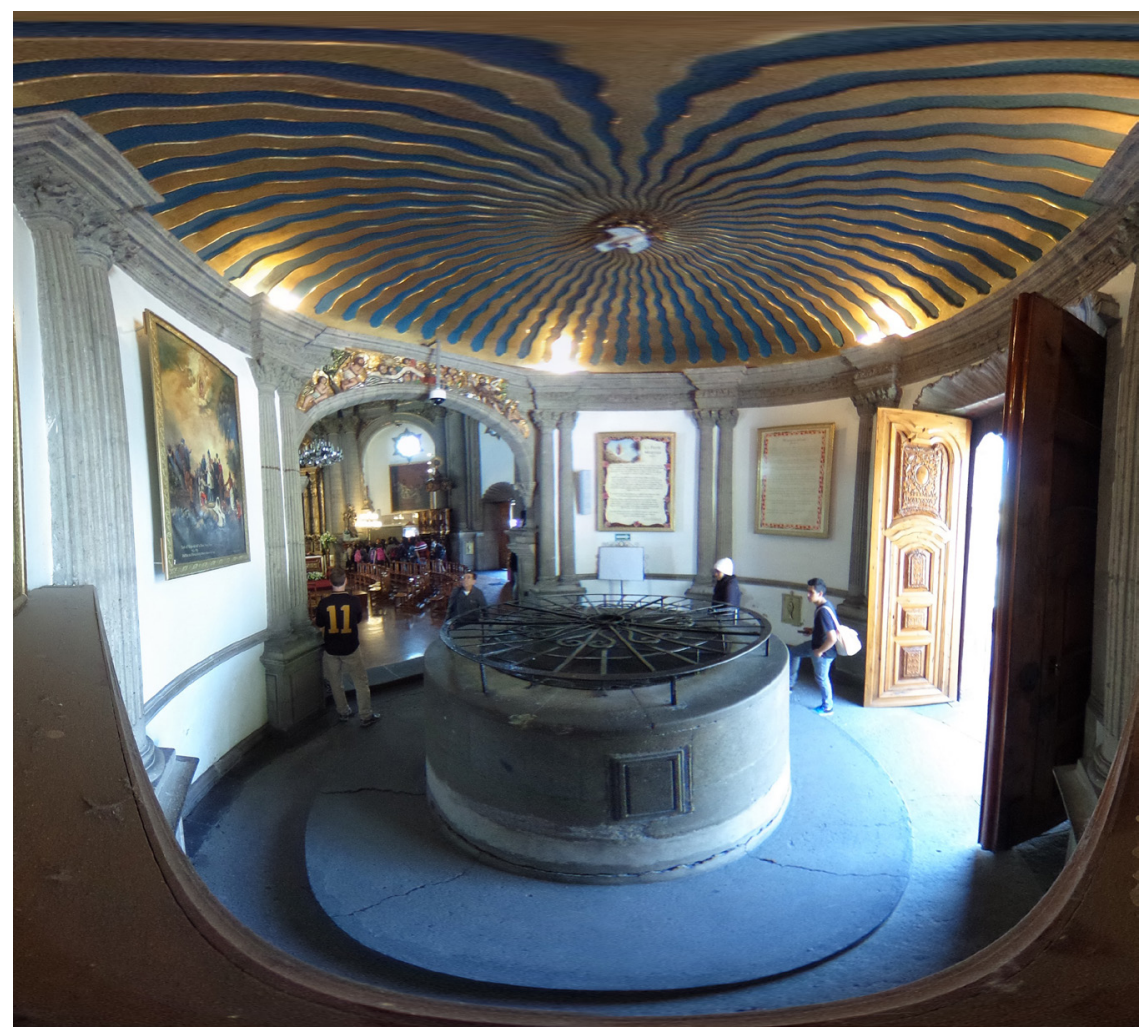

FIGURE 24. El Pocito, Villa de Guadalupe, 2017. Photograph by author.

water drawn from a well-the springs, exhausted by groundwater pumping, no longer bubble to the surface (see Figure 1). Everyone who goes there is convinced of the medicinal efficacy of bathing in the waters, but few others even know about them, least of all doctors. Like the tourism industry, the medical profession no longer depends on mineral waters such as those of Peñón or Ixtapan; it seems that most doctors share the view of water as homogeneous and inert, good for washing.

Despite the general decline of mineral spring bathing during the twentieth century, heterogeneous waters still exist, and people are still drawn to them for cultural reasons that have accumulated over centuries. Drinking is the most common interaction with mineral waters today, and it is clearly enjoying an immense upwelling of popularity. In a few cases-Tehuacán, Peñafiel, and Topo Chico-the mineral springs have been captured for bottling, and these waters are indeed well known. Like all bottled waters today, mineral waters appeal to consumers because of their specificity-the fact that they are not tap water. Bottled waters are felt to be purer and safer than tap water, and those that claim an attractive origin- "bottled 
at the source"-are especially desired. The "Tehuacán" brand, for example, says that its water originates at the top of the Pico de Orizaba, a nearby volcano. ${ }^{4}$ Mineral waters such as Topo Chico, Peñafiel, and Tehuacán carry these connotations of purity derived from geographical specificity, but their perceived virtues go beyond purity to include the efficacy of their mineral contents. Mineral water is seen to help digestion, and the chemical contents of the waters are sometimes displayed on the label as if they were medicine. Long-standing ideas about the influence of the environment on human health animate the ingestion of bottled mineral waters, and mineral waters remain virtuous and efficacious in the minds of many consumers, in Mexico and around the world.

Bathing is now a less-common form of interaction with mineral waters, but many hot springs remain popular as mass tourist destinations, and longstanding concepts of the healthfulness of immersion in these waters are still held by those who visit them. I spent many afternoons, for example, in the hot spring pools of the Balneario Municipal in Ixtapan de la Sal, chatting with the visitors. Sitting together in the hot pools, we would discuss the virtues of the waters, and how they acted upon the body to ease problems of gout, arthritis, high blood pressure, circulation, etc. The salt in the water was good for allergies; the dissolved carbonate gas soothed the nerves. The mud we smeared on faces, arms, and bodies kept our skin smooth and youthful. Scientific proof of the efficacy of the waters was in plain sight: hung on the walls were analyses of their chemical composition. Also common, however, were stories of miraculous cures. One woman told of a deep scar that was made invisible by the waters; another witnessed a man enter in a wheelchair and leave walking. Bathing in these waters was a deeply social activity, sitting elbow to elbow in the water and talking about how it soothed our maladies.

What can we learn from these waters and cultures? What is their place in the twenty-first century? I have approached this complex multifaceted history from an historical, anthropological perspective that views human relations with the environment in a holistic way, informed by political ecology and its emphasis on social organization, conflict, and materiality. The history of waters and cultures in Mexico shows complex dialectics: heterogeneity and homogeneity; curing and contagion; social and individual; and a subject/object dynamic that posits water as both an inert substance to be controlled by humans, and as an efficacious, agential substance that works changes on humans. One of the trends in this history is toward the expansion of infrastructure and an associated individualization of our contact with water. Bathing for cleanliness has moved from public spaces to private ones. Shared bathhouses have given way to private bathrooms in people's dwellings. But this is not a unilineal process of water displacing waters; homogeneity has not abolished heterogeneity. Rather, the effort to create a sanitized, uniform, public water during the nineteenth and twentieth centuries actually strengthened the identities and values of specific waters, and we see that social bathing for fun, 
fitness, and therapy continued to flourish alongside the shower. Sit in any hot spring in Mexico, and this is evident.

Waters define social groups and their boundaries. Despite the individualization of bathing, our engagements with water are still organized around group identities. Soaking in a small pool of water with dozens of perfect strangers is something that many people are uncomfortable with, because intimacy probes the borders of race, class, ethnicity, sex, and gender that our society is built upon. Wealthy clients of Mexico City's bathhouses in the 1790 s bathed in private placeres, away from the temazcales and shared waters of the plebe. A century later the rich bathed in the privacy of their own homes in order to escape the massification of bathing. Social and sexual intimacy in the temazcales of New Spain was enough to engender a fullscale colonial clampdown; sex in the baths during the Porfiriato was greeted with a similar reaction. Boundary work is also busy at the borders of race and class. In Ixtapan de la Sal, the municipal bathhouse was built to cater to locals and people of more humble economic means; the hot springs at the Hotel Ixtapan served the wealthy. Today, the town's hot springs serve a wide cross-section of society, but those with a lot of money retire to more exclusive spas that have no mineral waters at all.

Along with the social distinctions that organize social practices of bathing, an important dynamic in the history of heterogeneous waters is the ebb and flow of interest by capital in them. The bathhouse at Peñón was renovated and served wealthy clientele in the late eighteenth century, and then again in the late nineteenth century. All along, however, humble Mexicans made use of the waters, pushing back against businessmen and governments in order to retain access to the common resource. Hydraulic opulence in the late-nineteenth century fomented the business of bathing and made these waters accessible to many more Mexicans. In Spain and other areas of Europe, elite interest in mineral waters declined during the mid-twentieth century, when public health systems enabled wide access by the middle class and even poor. With the decline of the welfare state, elite spas are once again on the rise, as these commons are privatized and investors eye the business of bathing as an attractive way to tap the wealth of the rich. Throughout Mexico, however, access to mineral springs remains fairly open, conserved that way in many cases by municipal and ejidal ownership and administration. It remains to be seen if another wave of primitive accumulation will turn the popular spas of Mexico into luxury resorts, but the strength and persistence of Mexican water cultures and their traditions of access make such an outcome seem unlikely.

Cultures of waters deserve our attention. Most of what we know about our relation to water has to do with the macroenvironmental aspects of irrigated agriculture and urban water systems. But waters move through our bodies and intimate social spaces as well, and scholars have largely ignored these topics. As the world confronts a generalized water crisis, intimate engagements with waters will surely play a role in reconstructing a more sustainable relationship with the liquid. Already the 
strategy of increasing supply through the construction of ever-expanding storage and conveyance infrastructures has been rejected in favor of demand management, which pivots around reducing domestic water use in urban contexts. More efficient bathing practices are in order; shorter, less frequent, perhaps shared engagements with water. Ancestral water cultures present a range of affective values that may point us toward less destructive uses. We fill our bathroom drains and public water infrastructures with soap and shampoo, but we might not be comfortable about dumping these substances in a pond that we drink from and swim in. A return to feeling and valuing the specificity of heterogeneous waters and promoting of interactions with them could limit the destructive aspects of the modernist illusion of unlimited, homogeneous water disconnected from our bodies and lives.

Virtuous waters, past and present, convey elements of more sustainable relationships with the environment and with each other. Unfortunately, building a sustainable relationship to water is not simply a question of replacing one cultural element with another. Heterogeneity, for example, contributes content to our dysfunctional and maladaptive relationship with water, as evidenced by the recent boom of bottled waters. These waters are sold as unique and geographically specific: sometimes they are, often they are not. Regardless, the production of billions of plastic water bottles drives up costs for the liquid, pollutes our rivers and oceans, and generates fabulous profits for the few while defunding the public water systems that do the same job much more efficiently. ${ }^{5}$ Heterogeneity lies at the heart of the commodity form, and this complicity promises to cause mischief as we chart a course toward more local, more intimate engagements with the hydrosphere.

Renovating our relationship with our waters requires a focus on, well, relations: with water but also with each other. The search for profit that lies at the heart of our economic system will relentlessly define the liquid by the part it plays in the accumulation process. It may be a resource that provides rents through irrigated agriculture, or it can generate profits through bottling and sale as a commodity. However, the quest for profit propels the business of bathing and bottling unevenly, in cycles and surges, never fully eradicating the relations of community and cooperation that ensure access to springs at places such as Peñón and Ixtapan, or erasing deep-seated ideas about the virtues of the liquid. The control of mineral waters by some people through law, science, technology, and sometimes outright force was and still is resisted with some success by other groups of people. As we struggle toward a more sustainable relationship to waters, we may find that these deep, long-standing relationships that everyday people have with waters and with each other can serve as a fountain of ideas and practices for building more virtuous cultures of waters. 